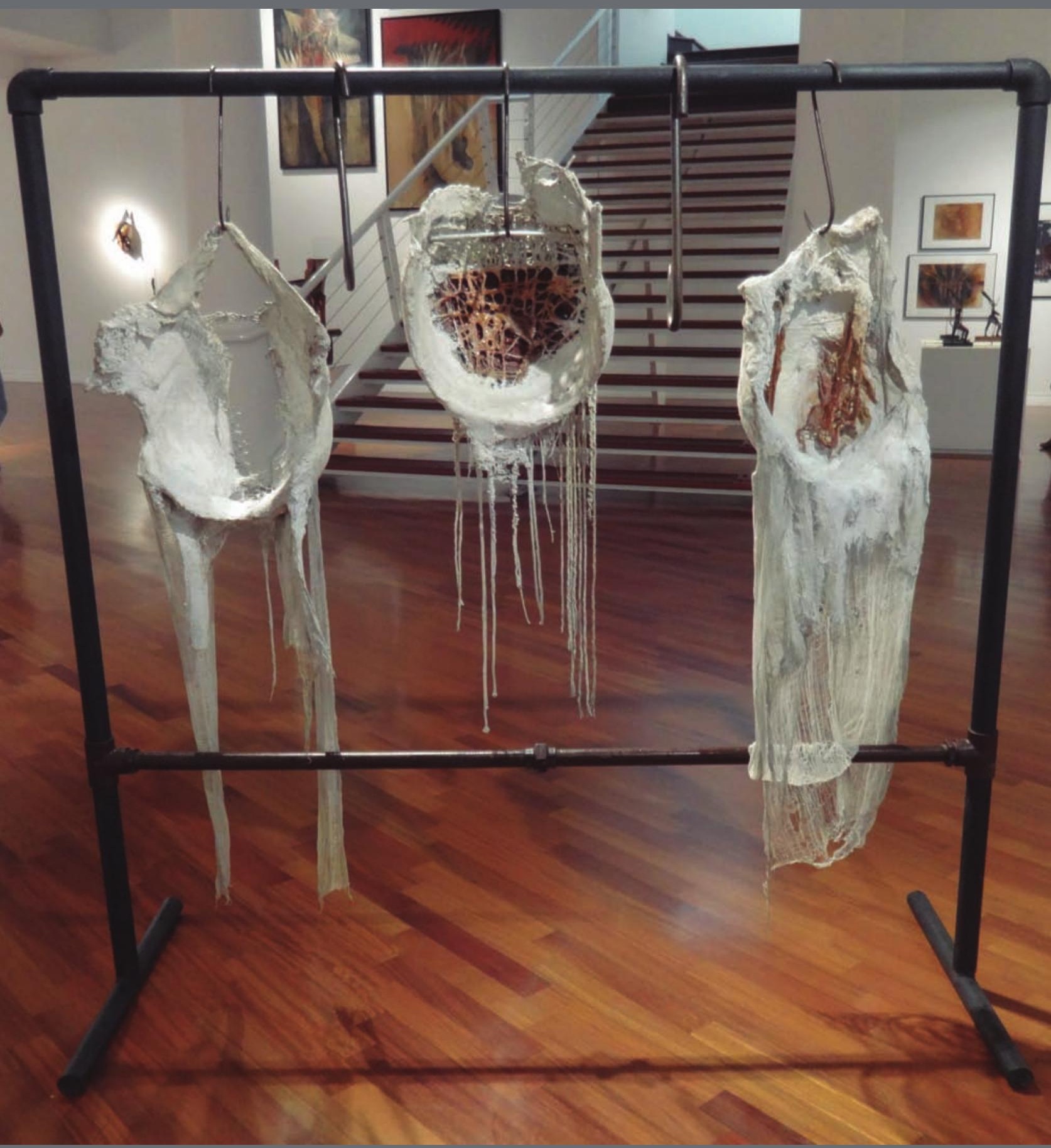

Fig. 1. Barrigas. Johanna Hamann. 


\title{
Una espera en tres actos. Vientres grávidos (y gravitantes) en la plástica peruana de los ochenta
}

Manuel Munive Maco Investigador independiente zambacanutafilms@gmail.com

\section{Resumen}

Entre 1983 y 1990 se expusieron en Lima tres piezas realizadas por tres artistas jóvenes -formados como escultora, pintor y diseñadora gráfica, respectivamente-, las cuales coincidían en representar, velada o explícitamente, vientres preñados. Y si bien cada uno abordó la metáfora de la gravidez de un modo singular, esta estuvo determinada, básicamente, por la elocuencia de los materiales que le dieron cuerpo. Este breve trabajo ofrece una lectura concatenada de esas notables piezas gracias a la perspectiva que otorga el tiempo transcurrido.

Palabras clave: escultura, pintura, diseño gráfico, Johanna Hamann, Eduardo Tokeshi, Patricia Vega.

\begin{abstract}
Between 1983 and 1990, three pieces of art made by three young artists - trained as a sculptor, artist and graphic designer, respectively - were exhibited in Lima. They coincided in representing, implicitly or explicitly, pregnant bellies, although each one approached the metaphor of pregnancy in a singular way that was determined, basically, by the eloquence of the materials that gave body to the art piece. This short work offers a concatenated reading of those remarkable pieces thanks to the perspective given by the elapsed time.
\end{abstract}

Keywords: sculpture, painting, graphic design, Johanna Hamann, Eduardo Tokeshi, Patricia Vega.

\section{Introducción}

¿Cuánto tiempo debe pasar para que un objeto -sea este una pintura, una escultura, una fotografía, un ensamblaje o una instalación- adquiera la categoría de obra de arte? ¿Cuándo podremos saber si las piezas que se exponen hoy, a inicios de octubre del 2017, en diversos puntos del magro circuito galerístico de Lima, se consagrarán efectivamente como obras? Porque si algo parece cierto en el incierto mundo valorativo del arte es que, más allá de lo que pueda hacer un crítico, un curador o un coleccionista, es finalmente el tiempo quien se encarga, pacientemente, de esa necesaria misión depurativa.

En las siguientes líneas trataremos sobre tres piezas elaboradas por tres artistas limeños que consolidaron sus personalidades creativas, específicamente durante la segunda mitad de la década de los años ochenta del siglo pasado, un periodo histórico particularmente 
difícil que, sin embargo, parece haber sido estimulante a pesar de las adversidades, como lo deja ver un análisis de sus trayectorias y la de muchos de sus pares.

Lamentablemente, la escasez de recintos expositivos en nuestro medio hace que sea casi imposible que el público pueda acceder permanentemente a las obras producidas por los artistas activos durante aquella época, y ha sido gracias a las exhibiciones temporales, antológicas o retrospectivas de su trabajo -y a las publicaciones ilustradas que las complementaron-, que hemos podido reevaluarlo y comprobar cómo treinta años después permanece incólume y cargado de más significaciones ${ }^{1}$.

Pero al no estar a la vista, esas obras no solo se quedan fuera del marco referencial cultural del público, sino que se las priva de algo más trascendental: esto es, contribuir a la formación de los artistas peruanos más jóvenes, impidiéndoles incorporar reflexivamente ese conocimiento -esa experiencia- en sus propios procesos creativos y, sobre todo, el ser conscientes de todo el trabajo producido en su propia ciudad unas cuantas décadas atrás.

Estos tres objetos artísticos, una instalación escultórica y dos ensamblajes o cuadros no pictóricos, coinciden en emplear el embarazo o la preñez como metáfora: Barrigas, de la escultora Johanna Hamann, expuesta por primera vez en su individual de 1983, en la galería Camino Brent; Bandera IV, del pintor Eduardo Tokeshi, culminada y expuesta en 1987, en la sala Miroquesada Garland; y Nacer en Lima, de la entonces diseñadora gráfica Patricia Vega, la cual integró su muestra personal de 1990, en la galería L'Imaginaire de la Alianza Francesa de Miraflores.

Tres versiones plásticas de una vivencia biológica exclusivamente femenina que al ser producidas y expuestas durante un periodo de extrema violencia y muerte planteaban complejas lecturas acerca de concebir y engendrar, las cuales, vistas desde ahora, parecieron articular un discurso concatenado acerca de la significación psíquica de seguir vivos. ¿Qué puede significar esa recurrencia temática producida en el espacio de siete años en una escena cultural tan pequeña como la de aquellos años? En las siguientes líneas trataré de aportar algunas ideas al respecto.

Cada una de estas tres piezas, a su vez, se ha ganado por derecho propio la categoría de hitos o iconos visuales y culturales imprescindibles para indagar sobre la psiquis colectiva que imperó particularmente en esos años duros para el Perú, y sobre cuyas secuelas seguimos reflexionando. Más de una vez han compartido el guion museográfico de diversas miradas curatoriales y en cada participación no solo resultaron cruciales, sino que no se agotaron, como parece que suele ocurrir con el arte auténtico ${ }^{2}$.

\section{Marco temporal}

Para dotar de una cronología a estas obras recurrí a la periodización del Conflicto Armado Interno propuesta por la Comisión de la Verdad y la Reconciliación en su informe final:

1. "El inicio de la violencia armada (...) comprende desde el primer acto de violencia cometido por el terrorismo senderista, en Chuschi, Cangallo, el 17 de

1 Además de los artistas cuyas obras tratamos aquí, hemos podido reencontrarnos, gracias a esas grandes exhibiciones, con el trabajo ochentero de artistas tan importantes como Carlos Runcie Tanaka, Herman Schwarz, Jaime Higa, Herbert Rodríguez o Alina Canziani. Sin embargo, es necesario que suceda lo mismo con la producción de Ricardo Wiesse, Jorge Castilla-Bambarén, Javier Aldana, Luis García- Zapatero, entre algunos otros, como la del también recientemente desaparecido Anselmo Carrera.

2 Al terminar de escribir este, artículo Carlos Runcie Tanaka me advirtió que "Barrigas" se encontraba en el Hammer Museum de Los Ángeles, integrando la muestra Radical Women: Latin American Art, 1960-1985 inaugurada el 15 de septiembre último. La curaduría de esta exhibición, la cual permanecerá abierta hasta el 31 de diciembre, estuvo a cargo de las teóricas Cecilia Fajardo-Hill y Andrea Giunta e incluye la producción de 120 artistas mujeres latinoamericanas. 
mayo de 1980, hasta la disposición presidencial del 29 de diciembre de 1982 que estableció el ingreso de las Fuerzas Armadas en la lucha contrasubversiva en Ayacucho".

2. "La militarización del conflicto (...) abarca desde la instalación, el 1 de enero de 1983 del comando político-militar de Ayacucho a cargo del general Roberto Clemente Noel Moral, hasta la matanza de los penales del 18 y 19 de junio de 1986".

3. "El despliegue nacional de la violencia (...) se desarrolla desde la mencionada matanza de los penales de junio de 1986 hasta el 27 de marzo de 1989, fecha del ataque senderista, con el apoyo de narcotraficantes, al puesto oficial de Uchiza en el departamento de San Martín".

4. "La crisis extrema, ofensiva subversiva y contraofensiva estatal (...) se inicia inmediatamente después del asalto senderista al puesto de Uchiza y concluye el 22 de septiembre de 1992 con la captura en Lima de Abimael Guzmán Reinoso y de los principales dirigentes de su organización por parte del GEIN".

5. "Declive de la acción subversiva, autoritarismo y corrupción (...) comienza con la captura de Abimael Guzmán y la cúpula senderista, y se extiende hasta el abandono del país del ingeniero Alberto Fujimori en noviembre de 2000”. (2004, pp. 61-62).

Johanna Hamann empieza la elaboración de sus Barrigas aproximadamente en 1978 y la culmina en 1983, año en el que la exhibe por primera vez en su primera muestra personal en la Galería Forum, lo que permite decir que la historia de esa pieza se desarrolla durante el primer periodo mencionado y se exhibe poco después del inicio del segundo. Eduardo Tokeshi inicia la primera serie de sus Banderas en 1985 y la culmina en 1994. Su Bandera IV, la pieza que nos interesa destacar, queda lista en 1987, poco después del inicio del llamado despliegue nacional de la violencia. Nacer en Lima, de Patricia Vega, es mostrada por primera vez en 1990, cuando ya nos encontrábamos de lleno en la fase denominada crisis extrema ${ }^{3}$ (Villacorta, 2016, p. 164).

\section{Barrigas (1978-1983). Del vientre henchido al vientre vaciado}

Quizás desde la época inicial, desde mis primeras esculturas -Niño, Cabeza, Barrigas - he estado más cerca de mí físicamente. (...) Barrigas, por ejemplo, son una pregunta: ¿es un nacimiento, un aborto, qué es? Todas las materializaciones artísticas son siempre, por lo menos las que yo hago, preguntas; preguntas que me he hecho y que manifiesto y que se quedan como preguntas ahí. (Ibidem, pp. 164).

Antes de verla directamente en una de las salas de exposiciones temporales del Museo de Arte y de Historia de San Marcos, donde, como muchos estudiantes del programa de Historia del Arte, recalé para hacer prácticas, conocí las Barrigas de Johanna Hamman ${ }^{4}$ mediante su reproducción fotográfica en blanco y negro publicada en el número 18 de la revista Hueso Húmero (1983). Una de mis funciones como practicante era hacer visitas guiadas para el público que empezaba a acudir lentamente al museo, que funciona desde

3 Barrigas se conserva en el Museo de Arte de Lima; la Bandera IV se encuentra en una colección privada y Nacer en Lima integra la colección particular del ceramista y escultor Carlos Runcie Tanaka.

4 Johanna Hamann Mazuré. Escultora y grabadora peruana nacida en Lima en 1954. Estudió en la Facultad de Artes Plásticas de la Pontificia Universidad Católica del Perú entre 1971 y 1976. Realizó siete exposiciones individuales y una muestra antológica el año 2016 en la sala del ICPNA de Miraflores. Participó en la VI Bienal de Grabado Latinoamericano en San Juan de Puerto Rico (Puerto Rico, 1983); en la II Bienal de Trujillo (Perú, 1985); en la II Bienal de La Habana (Cuba, 1986); y en la I Bienal Arte y Empresa en el Museo de Arte de Lima (1990). Participó en numerosas exposiciones colectivas. Falleció en Lima el año 2017. 


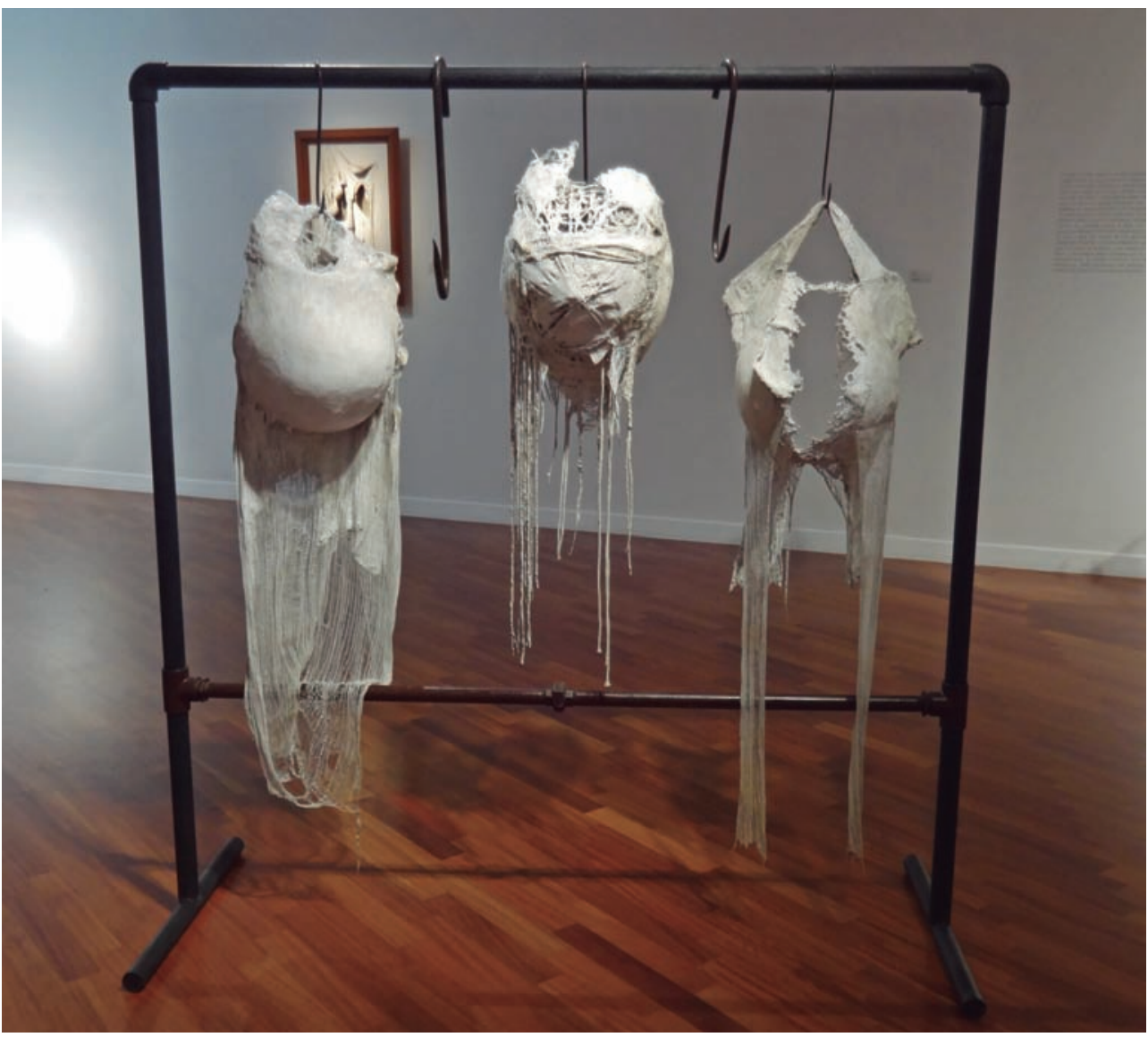

Fig. 2. Barrigas. Johanna Hamann.

su fundación en el centro cultural sanmarquino, más conocido como Casona, y esto me permitió corroborar, sucesivamente, la perturbadora impresión que les suscitaba. Siempre quise preguntarle a la autora sobre el proceso de ejecución de esa emblemática pieza y grabar su testimonio, pero lo pospuse demasiado: la artista, lamentablemente, falleció hace unos meses, en abril del 2017, y nunca pude entrevistarla, aun cuando compartimos un par de proyectos de trabajo en común. Afortunadamente, el catálogo editado con motivo de la muestra antológica de su obra montada en el 2016 contiene una extensa y acuciosa entrevista realizada por Jorge Villacorta, donde la artista abunda sobre la historia de las Barrigas. Fig.1.

En esa entrevista, Johanna Hamann deja en claro que esta obra:

- No fue realizada como un símil de su propio embarazo -pues su hijo nació en 1977-y que de ningún modo resultó de un molde de su propio vientre.

- Que el propósito detrás de Barrigas fue, principalmente, el de manifestarse contra el rol que la maternidad impone automáticamente sobre el destino social de cualquier mujer.

Técnicamente, Barrigas es un tríptico, pues presenta un correlato temporal entre esos tres vientres, desde el más cerrado -aunque ya evidencia el desborde de sus fluidos- al que 
luce completamente vaciado, pasando por el central, cuya superficie erosionada deja a la vista el armazón que le otorga su forma esférica. Pero si esto puede resultar una innovación dentro de la historia de la escultura peruana, lo es más la estructura que la artista idea-después de descartar otras, como comenta en la entrevista mencionada- para que esos elementos pendan uno al lado del otro; me refiero a ese marco metálico sobre el cual se apoyan los garfios de carnicería que los sostendrán. Esa solución original y sin precedentes locales es la que permite que clasifiquemos esa obra como una instalación escultórica. Curiosamente, dicha estructura, que equivale también a una solución museográfica, solo encon-

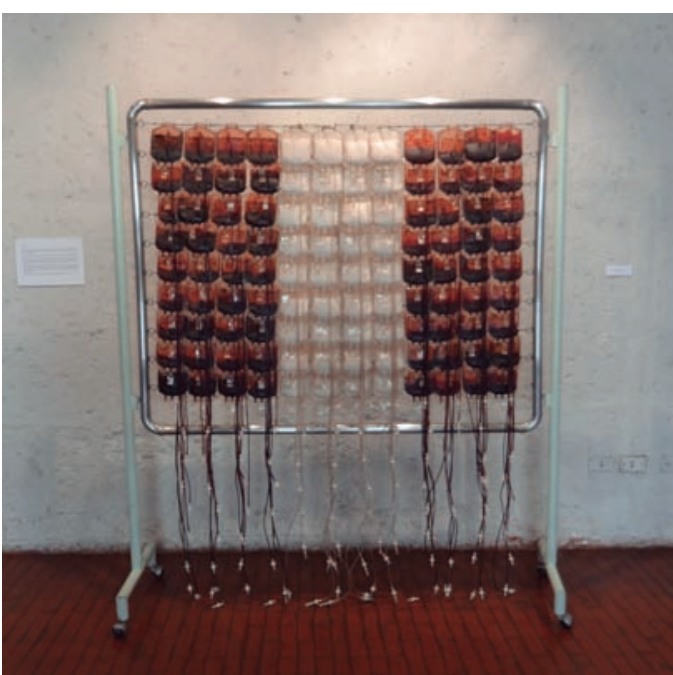

Fig. 2. Bandera VIII. Eduardo Tokeshi. trará su similar en otra pieza de Tokeshi: la Bandera VIII, culminada mucho tiempo después, en el 2000. Fig. 2.

Pero Barrigas, al igual que las otras dos piezas que revisaremos en este escrito, emana sentido desde su materialidad; hemos citado ya los hierros de matarife pero no podemos soslayar la gasa y el yeso, que inteligentemente evocan una fragilidad clínica. Si la escayola es una materia con la cual el escultor educado académicamente está familiarizado, como fue el caso de Hamann, cuando adopta formas orgánicas y entra en contacto con el hierro afilado, adquiere connotaciones quirúrgicas.

Si bien el testimonio de un artista puede arrojar algunas luces sobre diversos aspectos de su proceso creativo, este no explica por qué una u otra obra llega a trascender. Por eso resultan más reveladoras las lecturas sucesivas que los diversos espectadores hacen en momentos distintos, las cuales de alguna manera la van enriqueciendo y renovando y la convierten, progresivamente, en un patrimonio cultural -y poético- común. Por ejemplo, una de las primeras críticas a esa primera muestra personal de Hamann subraya acerca de la artista:

Su llana posición ante la vida se traduce en una obra sin explícitas referencias a la actualidad política de su entorno, pero con profundas marcas de una situación social en la que los límites se sienten cada vez más cercanos, en la que los conceptos elaborados se hacen superfluos, en la que los peligros de la convivencia con nosotros mismos transportan su atención a carne propia y la alejan de la especulación teórica. (Jarque, 1983, pp. 166-167).

Apenas cuatro años después, específicamente en una publicación periódica de marzo de 1987, Alberto Flores Galindo hace una interpretación sombría de Barrigas, intuyendo que se trata de una prefiguración de los malos tiempos por venir:

Estos fantasmas, que cada vez se tornan más reales, fueron tiempo atrás avizorados por las artes plásticas. La pintura y la escultura, con frecuencia en el país, se adelantan a la reflexión social. Allí están esos monstruos verdosos de Tola, los cadáveres yacentes de Charo Noriega, la maternidad abortada y desgarrada en las carnes colgantes esculpidas por Johanna Hamann. (Flores Galindo, 1987, p.123). 
Fig. 3. Bandera IV. Eduardo Tokeshi.

Foto: Archivo ICPNA.

Esta reacción es comprensible, pues en el lapso transcurrido entre la publicación del número 18 de Hueso Húmero y el primero de Márgenes, el terrorismo había desatado ya, palpablemente, la espiral de muerte que convirtió algunas zonas de andinas del Perú en lugares de los cuales había que huir ${ }^{5}$.

\section{Bandera IV (1987). Alumbramiento y exhumación}

El distanciamiento con el hecho orgánico de parir que expresó Hamann cuando se le interrogó sobre la influencia que pudo haber tenido su propia maternidad en la elaboración de Barrigas, parece consolidarse en el caso de la Bandera IV, pues su autor es un artista varón. Eduardo Tokeshi pudo aproximarse al tema de la preñez en frío, como una metáfora más críptica, o ambivalente si se quiere, y no como la reacción a una experiencia biológica. Fig. 3.

5 El informe final de la Comisión de la Verdad y la Reconciliación enumera los principales crímenes perpetrados entre enero de 1983 y junio de 1986: Se produjeron casos de violaciones masivas de los derechos humanos atribuidos a las fuerzas del orden como los de Socos (Sinchis de la ex GC, en noviembre de 1983), Pucayacu (infantes de Marina, agosto de 1984), Putis (infantería del Ejército, diciembre de 1984) y Accomarca (infantería del Ejército, agosto de 1985). Y los crímenes del terrorismo senderista fueron los “de Lucanamarca y Huancasancos (abril de 1983)". p. 68. 
Eduardo Tokeshi ${ }^{6}$ se formó también en la misma facultad que Hamann, en la especialidad de Pintura. La Bandera IV forma parte de una serie de cuadros/ensamblaje realizada en, al menos, dos etapas. Bandera IV es la última de esa primera etapa, la que comprende los años 1983 y $1987^{7}$. Ese conjunto también formó parte de la colección del museo sanmarquino durante algunos años, lo que me facilitó apreciarla de cerca muchísimas veces e implicaba, además, que me ocupara periódicamente de su conservación preventiva entre los años 1996 y $1999^{8}$.

Hasta hoy, me resulta inevitable no hacer una lectura personal ambivalente de la Bandera $I V$, pues siempre me pareció, simultáneamente, un vientre en trance de parir y una suerte de ojo/vulva. La bandera peruana reconocible en esa precaria pero indudable bicromía patriótica pugna por salir, se asoma como una bolsa placentaria, pero también como una hernia. Aquello que emerge, en trance de ser alumbrado, es una anomalía. Los campos de color rojo de esa bandera/globo ocular que nos atisba entre esos párpados de plástico negro fueron pintados desprolijamente adrede, y esa imperfección aportaba una cuota de humanidad a la pieza.

Esta bandera era, además, la única pieza de la serie en la que el volumen adherido/adosado deja de aludir a un cuerpo completo o fraccionado, y es la única que privilegia un material no textil para definirla: me refiero al plástico negro que sirve tanto para envolver los cadáveres recuperados después de una pericia forense como para deshacernos de los desperdicios domésticos. En este caso, la manga de plástico negro funciona como una lisa y pulquérrima epidermis que se abre para parir/expulsar algo que, antes que un despojo humano, parece un tejido vivo. ${ }^{9}$

Conviene mencionar que en un número importante de los trabajos realizados a mediados de la década de los ochenta, Tokeshi recurre a templar los materiales textiles empleados -tocuyo, yute, etc.- y esas tensiones, sin duda, resultan de una lectura personal del trabajo de otro artista, el también peruano Jorge Eduardo Eielson, con quien algunos creadores jóvenes de aquella generación guardaban una relación de admiración. Creo que fue a partir de la lección Eielson que Tokeshi descubre la capacidad expresiva de los materiales extra artísticos.

¿Pero era posible que las Barrigas de Hamann hayan tenido que ver de alguna manera con la historia de la Bandera IV? Tokeshi despejó nuestras interrogantes:

En este caso no tuvo relación. Usualmente mis referentes son múltiples pero en este caso es la enfermedad, la relación entre el mal y el interior. La bandera tiene más de las películas de Cronenberg que la estética de lo visceral no dicho. El mal más como silencio que como evidencia. (...) Las banderas son un proceso abierto y es totalmente coyuntural. Las banderas fueron y son síntomas, apuntes, malestares, comentarios, pero ante todo son mecanismos de reafirmación de identidad. ${ }^{10}$

6 Eduardo Tokeshi Namizato. Artista visual nacido en Lima en 1960. Entre 1978 y 1980 estudió en la Facultad de Arquitectura y Urbanismo de la Universidad Federico Villarreal, y entre 1981 y 1986 en la Facultad de Artes Plásticas de la Pontificia Universidad Católica del Perú, donde obtuvo la licenciatura en Pintura, en 1992. Ha realizado varias muestras individuales y dos retrospectivas de su obra en Lima y Arequipa, en los años 2012 y 2016, respectivamente. Vive y trabaja en Lima.

7 La serie se prolongaría desde inicios de los noventa en una segunda fase.

8 Fue durante ese lapso que comprendí lo importante de contar con espacios comunes de contemplación para obras como aquella, las cuales podían resultar perturbadoras para cualquier coleccionista privado, pero que hallaban en un museo como el sanmarquino su espacio idóneo. Esa y algunas otras piezas igualmente notables que se preservaban entonces en ese museo formaron mi sensibilidad y me aproximaron al ámbito de la plástica contemporánea.

9 Si revisamos cada uno de estos ensamblajes, veremos que la figura humana sugerida adopta la forma de cuerpo yacente dispuesto sobre una camilla de mano, envuelto en un sudario, o ya casi irreconocible como de un despojo. Debemos precisar aquí que el plástico negro aparece por primera vez en la obra Uchuraccay, realizada por Tokeshi y Jaime Higa entre 1985 y 1987.

10 Información proporcionada por E. Tokeshi el martes 10 de octubre del 2017, mediante correspondencia electrónica. 


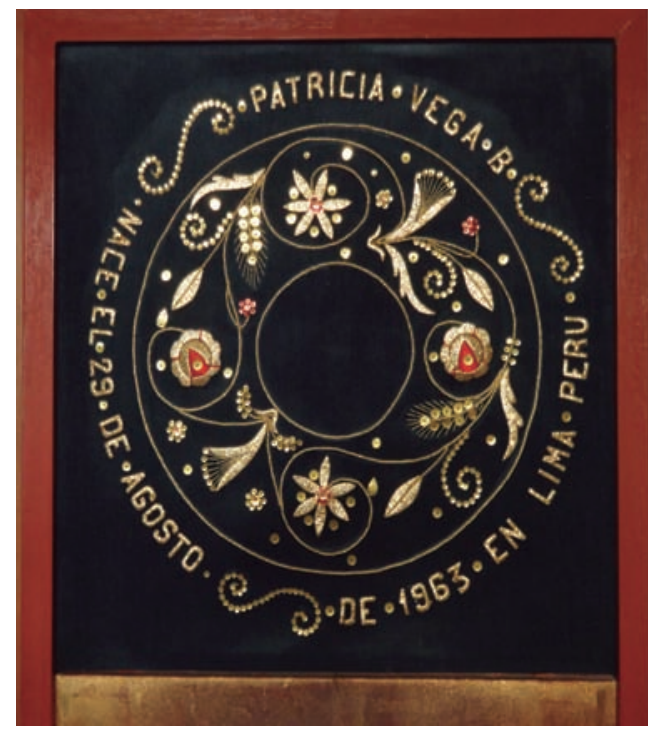

Patricia Vega. Nacer en Lima. Terciopelo, bordado, pan de bronce y fibra de vidrio sobre trupan. 133 x $69 \mathrm{~cm} .1990$. Foto: Manuel Munive.

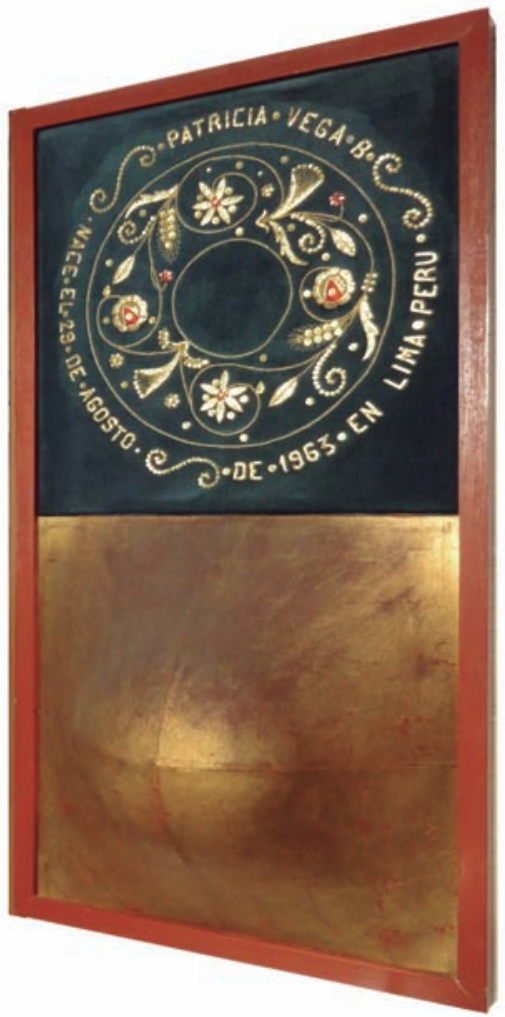

Sobre los aspectos técnicos de la Bandera $I V$, Tokeshi añade:

Mi proceso es muy riguroso y lo fue más aún con las banderas. No permite variaciones una vez iniciado. (...) El soporte es un bastidor de madera -con un MDF para aumentar la rigidez- lona, pintura látex rojo bandera, algodón industrial, manga de plástico color negro, pasta acrílica, óleo, tuercas, arandelas y pernos de $3 / 4$.

\section{Nacer en Lima (1990). Vientre festivo}

Nací en Lima (...), en esta Lima compleja y mutilada, la Lima que se va y se viene, pero abajo; y esa otra Lima, la que crece vertiginosamente, la Lima de los noticieros, la Lima chicha, la Lima de mercados y plazas y oficios inusitados; y la Lima religiosa de procesiones y santos, golpes de pecho, banderitas y escapularios (...). Vi Lima siempre inundada de las más variadas expresiones de arte popular, de los orígenes más diversos, y hoy no puedo sino sucumbir ante su frescura y encanto, porque su lenguaje, con frecuencia inadvertido, posee la fuerza del arte que no tiene pretensiones de serlo ${ }^{11}$.

El periplo de Patricia Vega Boschiazzo ${ }^{12}$ se inicia también en la Facultad de Arte de la Universidad Católica, pero en la especialidad de Diseño Gráfico. No es la primera artista

11 Texto de la artista publicado en el catálogo de la exposición Nacer en Lima (1990).

12 Patricia Vega Boschiazzo. Artista peruana nacida en Lima en 1963. Estudió Diseño Gráfico en la Pontificia Universidad Católica del Perú entre 1981 y 1985 . Ha realizado numerosas muestras personales. Complementó su formación en la Escuela Rietveld de Amsterdam, ciudad donde vive y trabaja desde mediados de la década de los noventa. 
que tiene una formación en artes gráficas. Por el contrario, ese salto de una especialidad de naturaleza utilitaria a las artes plásticas, es precisamente el signo que ha marcado el trabajo del artista posmoderno que transita por diferentes disciplinas para articular su propia metodología de trabajo y erigir así su propio lenguaje.

Nacer en Lima, desde el título, se constituye en un manifiesto personal que remarca la especificidad de haber nacido en la capital de un país que atraviesa un proceso complejo y convulso pero, a la vez, entraña cierto optimismo, el cual se evidencia en el refulgente vientre dorado que emerge del plano y en los materiales y las técnicas que completan este singular díptico vertical, y que simbolizan la cultura de un gran segmento de las poblaciones migrantes que transformaron Lima en la Gran Lima.

“En 1984, Lima es ciudad de forasteros”, afirma Matos Mar (1988) en su clásico estudio13 y esa presencia multitudinaria -y religiosamente festiva- está consignada en Nacer en Lima. Es notable cómo la artista elabora un objeto que parece prefigurar la pronta salida de esa crisis terminal, la que se daría recién un par de años después.

Fue inevitable ceder a la tentación de interrogar a la artista sobre lo determinante de su experiencia personal con la maternidad en la ejecución de esta obra. Nos respondió ampliamente:

No, no era madre. Esa obra es del 1990 y mi hijo nació en el 94. No, no es un hito (...) ya había hecho otros vientres. A través de estas obras primeras hago uso del arte como un medio ritual de hacerme de lo que no tengo y necesito o exorcizar lo que me oprime. Hay una serie anterior a mi primera individual donde hago una serie de collages usando vestidos y otras prendas de vestir, donde pinto a la altura del vientre, los atributos de la Virgen María, el ciprés, la palmera, la escalera, las fuente, el espejo, pero hay otra donde hay fuego, por ejemplo. Yo trabajé desde siempre de forma muy intuitiva y así lo sigo haciendo ${ }^{14}$.

Insistí en la posibilidad de haberse visto influida por las obras de Hamann y Tokeshi:

No recuerdo haberlas visto especialmente. La Bandera IV no sé cuál es. (La he buscado en la web pero no la encontré). Muy posiblemente haya visitado ambas exposiciones pero no diría que ellos me hayan influenciado. Por supuesto que creo que lo que uno ve, pero sobre todo lo que te mueve y sientes cercano a tu búsqueda, algunas veces se trasluce en tu obra. En esa época yo andaba muy interesada en la iconografía religiosa y popular; me fascinaba la pintura naïf y la pintura religiosa virreinal, las láminas escolares. Iba a menudo al centro de Lima por materiales.

Nacer en Lima formó parte de una muestra personal en la que se encontraban también otras piezas que evidenciaban un vínculo con la plástica tradicional y popular andinas, las cuales acusan, a su vez, un estrecho vínculo con el mundo mágico-religioso, por ejemplo, había explícitas alusiones a exvotos, como el caso del conjunto sin título, que está constituido por doce orejas de madera talladas en cedro y cubiertas por láminas de pan de bronce, las cuales se adosan a la pared siguiendo una distribución aleatoria ${ }^{15}$. (Tokeshi recorrerá también ese camino, lo que se evidenciará, por ejemplo, en sus obras Setenta veces siete y Vida y milagros del hombre invisible, de 1994 y 1997, respectivamente, en donde el artista inserta numerosos y genuinos exvotos metálicos. Aunque más velado, ese abrevar en la plástica

13 Matos Mar dice: "A julio de 1984 se puede afirmar que cerca del 50\% de la población urbana nacional, así como más del $30 \%$ de la población total del Perú, vive en la gran Lima. El centralismo limeño iniciado en el siglo XVI, adquiere ahora un nuevo carácter y dinámica. Esta concentración masiva somete las estructuras espaciales y sociales del mundo urbano a tensiones nunca vistas en el pasado del país” (1988, p.73).

14 Testimonio de la artista, enviado mediante correo electrónico del 2 de octubre del 2017.

15 Se encuentran también en la colección de Carlos Runcie Tanaka. 
andina se hace patente también en su reformulación y habilitación de las Tablas de Sarhua ayacuchanas como soporte pictórico.).

En efecto, las sucesivas migraciones que se instalan en la capital convierten algunos de sus sectores, y particularmente el Centro Histórico, en un coto de caza conceptual y material para el artista erudito, a donde acude para proveerse de estímulos e insumos.

El yo poético de Nacer en Lima es femenino no solo en la volumetría del vientre grávido, sino también por el tipo de caligrafía bordada, usualmente hecha por hombres, para prendas que se emplean tanto en festividades paganas como religiosas, promovidas por las innumerables comunidades andinas que se han constituido en la capital.

Al respecto, la artista agrega: "A los bordadores que trabajaron conmigo, los encontré en el centro que, como te decía, frecuentaba a menudo. Tenían muestras del trabajo que hacían y yo hice mi diseño usando el estilo de los bordados para los estandartes de las procesiones".

\section{Nacer-Resucitar-Renacer}

Hemos mencionado brevemente tres piezas de vocación escultórica, algo peculiar si recordamos que dos de ellas fueron elaboradas por un pintor y una diseñadora gráfica. Y este fue sin duda un signo en el trabajo de los mejores artistas jóvenes de los años ochenta, es decir, la necesaria ruptura con las fronteras disciplinarias y los formatos tradicionales, tal como lo evidencian las obras que acabamos de mencionar, así como otras elaboradas por otros autores y sobre las que trataré en otro momento. ${ }^{16}$

Desde su materialidad, la escayola y los garfios de carnicero en Barrigas (1983), la bolsa negra forense y el tocuyo en Bandera IV (1987), y el terciopelo bordado y el pan de bronce en Nacer en Lima (1990), plantean un discurso cuya elocuencia radica en la naturaleza material que los constituye y que se transparenta hoy, treinta años después. Formas gestadas de un proceso que requería de ese desborde formal para apelar a una corporalidad tangible, tridimensional y simbólica.

16 Este breve texto es, en verdad, el primero de otros semejantes que establecen vinculaciones formales y conceptuales entre piezas de esa época 


\section{Referencias bibliográficas}

Comisión de la Verdad y Reconciliación. (2004). Hatun willakuy. Versión abreviada del Informe Final de la Comisión de la Verdad y Reconciliación. Primera edición. Lima, Perú.

Flores Galindo, A. (1987). "Generación del 68: ilusión y realidad”. En: Márgenes. Encuentro y Debate. (Año 1, N. ${ }^{\circ}$ 1, marzo de 1987).

Jarque, F. (1983). "Johanna Hamann: el perfil de lo intacto”. En Hueso Húmero. 1983. Lima, Perú.
Matos Mar, J. (1988). Desborde popular y crisis del Estado. El nuevo rostro del Perú en la década de 1980, 7ª edición. Lima: Concytec.

Villacorta, J. (2016). "Buscando ese nudo sutil que tal vez sea el vacío. Una conversación entre Hamann y Villacorta". En Johanna Hamann. Lima: Instituto Cultural Peruano Norteamericano. 